\title{
Relationship Between Clinical and Radiographic Findings in Osteoarthritis Knee: A Cross-Sectional Study
}

\author{
Safaa A. Mahran ${ }^{1,2}$, MD, Amro Y. Elias², MBBS, Fadwa S. Janbi², EMHA, and \\ Basem S. El-Deek ${ }^{3}$, MD \\ 'Department of Physical Medicine, Rheumatology and Rehabilitation, Faculty of Medicine, \\ Assiut University, Assiut, Egypt \\ ${ }^{2}$ Department of Physical Medicine and Rehabilitation and ${ }^{3}$ Department of Medical Education, \\ Faculty of Medicine, King Abdulaziz University, Jeddah, Saudi Arabia
}

\section{Correspondence}

Dr. Safaa A. Mahran

P.O. Box 80215, Jeddah 21589, Saudi Arabia

e.M: sjamaluddin@kau.edu.sa

Submission: 27 Jan. 2015

Accepted: 1 Mar. 2015

\section{Citation}

Mahran SA, Elias AY, Janbi FS, El-Deek BS. Relationship between clinical and radiographic findings in osteoarthritis knee: a cross-sectional study. JKAU Med Sci 2015; 22 (2): 1-9. DOI: 10.4197/Med. 22.2.1

\begin{abstract}
Several studies have suggested that there is a high discrepancy between clinical and radiographic knee osteoarthritis. The objectives of this study were to examine association between radiographic classification and clinical manifestations of knee osteoarthritis, and to determine if the assessment of individual radiographic features was superior to the general radiographic scale in establishing such a relationship. A total of 125 patients with knee osteoarthritis were enrolled in this study. Radiographic features were assessed with the Kellgren-Lawrence grade scale for general radiographic grading, and a line-drawing atlas for detailed radiographic analysis. The severity of knee pain, stiffness, and disability were measured using the Western Ontario and McMaster Universities Osteoarthritis Index. Patients' age and pain duration were found to correlate significantly with knee pain, stiffness, and disability. No association between general radiographic grading scale and clinical manifestations was found. However in detailed radiographic analysis, osteophyte site at the patellofemoral joint was found to correlate with knee stiffness. In conclusion, radiographic scores were not found to be closely associated with the clinical features of knee osteoarthritis. The results of knee X-rays should not be used in isolation when a management decision is to be taken for patients with knee osteoarthritis.
\end{abstract}

\section{Keywords}

Knee osteoarthritis; Radiographic; Relationship; Symptoms

\section{Introduction}

steoarthritis (OA) is the most common degenerative joint disorder and a major public health problem throughout the world. It affects any joint containing hyaline cartilag ${ }^{[1,2]}$ and the knees are the most commonly affected joints ${ }^{[3]}$. Diagnosis of $\mathrm{OA}$ is usually based on symptoms (clinical OA) and is confirmed by radiography ${ }^{[4]}$. Pain is the predominant symptom of knee OA and the main reason for medical consultation. It is also a cause of disability, especially 
during painful episodes ${ }^{[5-7]}$. Various outcome measures for radiographic and clinical $O A$ are described in studies. In evaluation of clinical OA, the Western Ontario and McMaster Universities (WOMAC) OA Index scores for pain, stiffness and function ${ }^{[8,9]}$ are validated, and commonly used outcome measures. Common outcomes for radiographic OA are Kellgren-Lawrence $(\mathrm{K}-\mathrm{L})$ grading system ${ }^{[10]}$ and in recent years actual measurement of joint space width (JSW) has been increasingly applied ${ }^{[11,12]}$. The importance of multiple radiographic knee views has been recently illustrated. Inclusion of patellofemoral (PF) radiographs improves the sensitivity for identifying radiographic knee $\mathrm{OA}^{[13-}$ ${ }^{15]}$. Many physicians depend mainly on the radiographic features for planning rehabilitation or making joint replacement surgery decisions. Population studies have suggested that the 'fit' between X-rays and symptoms at the knee is not perfect ${ }^{[16]}$.

It is important that a clear understanding exists concerning the relationship between function and radiographic features. The objectives of this study were to examine (1) The association between the radiographic classification of knee $\mathrm{OA}$ and clinical manifestations, including pain, stiffness and physical function and (2) Whether the assessment of individual radiographic features shows a better association with clinical parameters than the general radiographic scale.

\section{Materials and Methods}

The protocol of this cross-sectional study was approved by the Research and Ethics Committee, King Abdulaziz University. Each subject provided written informed consent prior to entering the study. Between May 2012 and January 2014, one hundred and fifty four (154) adult patients with knee OA fulfilling the American College of Rheumatology (ACR) Criteria ${ }^{[17]}$ and who were presented consecutively at the Physical Medicine and Rehabilitation Clinic, were investigated for the inclusion eligibility to be recruited in this study. Of them, 125 patients were found to be eligible. Exclusion criteria were patients under 18 years of age, patients with other rheumatologic diseases, serious systemic illness, malignancy, history of knee surgery and patients who received intra-articular injections. Weight was measured to the nearest $0.1 \mathrm{~kg}$ after removal of shoes and heavy clothes using a digital hospital column scale (Seca North America, Chino CA USA). Height was measured to the nearest $0.1 \mathrm{~cm}$ without shoes using the telescopic measuring rod for the column scale. From these data, Body Mass Index (BMI) (weight/ height ${ }^{2}, \mathrm{~kg} / \mathrm{m}^{2}$ ) was calculated and classified according to the World Health Organization (WHO) criteria ${ }^{[18]}$. The WOMAC scale was used to measure pain, stiffness and physical function of each subject ${ }^{[8]}$. The scale consists of 24 items divided into 3 subscales: 5 for pain, 2 for stiffness and 17 for physical function. Each item is scored using the Likert Scale as: none, mild, moderate, severe, and extreme. These terms correspond to an ordinal scale of 0-4. The scores are summed for items in each subscale. A total WOMAC score is created by summing the items for all three subscales. The WOMAC Index has been used extensively in clinical trials, and has generally been shown to exhibit greater or comparable responsiveness to change than other tests. This varies however, for different subscales and types of interventions. The test-retest reliability of the WOMAC varies for the different subscales. The pain subscale has not been consistent across studies, but it generally meets the minimum standard. The physical function subscale is more consistent, and has stronger test-retest reliability. The stiffness subscale has shown low test-retest reliability ${ }^{[19]}$.

Radiographic assessment of the symptomatic knee(s) of each participant was done using 2 scales: Kellgren-Lawrence (K-L) grading scale of the posteroanterior (PA) films ${ }^{[10]}$, and a line drawing atlas for grading of knee $\mathrm{OA}^{[20]}$. In this study, three views for each symptomatic knee(s) were chosen: the fully extended weight bearing (PA) view for assessment of the tibiofemoral (TF) joint, and both the lateral supine view with the knee flexed to $45^{\circ}$ plus the skyline view for the assessment of the patellofemoral (PF) joint. Similar sensitivity was found between combination of PA plus skyline and PA plus lateral views ${ }^{[21]}$. Each radiograph was evaluated separately by two readers: M.S. and E.A., who were blind to patients' clinical details. The first reader, M.S. has over 20 years' experience in reading the musculoskeletal and joint radiographs as a senior consultant in physical medicine, rheumatology and rehabilitation, while E.A. has four years' experience reading knee $O A$ films as a senior resident physiatrist. In addition, E.A. underwent a period of initial training on the K-L scale interpretation. Each reader gave his score according to the K-L grading scale, followed by comparison of results. In cases with conflicting scores, the radiographs were re-read by both readers together to reach a common score. Next, the radiographs were assessed by the reader M.S. for the detailed line drawing atlas (LDA). The LDA ${ }^{[20]}$ was designed to overcome some of the theoretical and practical problems faced when using the photographic atlases of the Osteoarthritis 
Research Society International (OARSI). The LDA consists of a series of logically developed line drawings of the extended posteroinferior view of the medial and lateral tibiofemoral joints (TF) and skyline view of the PF joint for grading joint space width (JSW) and osteophyte. Osteophyte size was translated as $0=$ No osteophyte, 1 = Small osteophyte, 2 = Medium osteophyte and 3 = Large osteophyte. Where discrepancy existed in the score of osteophyte size within one site, the higher grade was chosen as a total grade, i.e. if the osteophyte size in the medial tibial area was scored 3 while in the medial femoral area was scored as 2, the osteophyte size in the medial TF compartment was given a score of 3. As in osteophyte size, joint space narrowing for each site was scored as $0=$ no narrowing, $1=$ mild narrowing, $2=$ moderate narrowing and $3=$ severe narrowing. The LDA improved and enhanced face and content validity compared with the OARSI atlas. Comparison of both atlases demonstrated similar reproducibility ${ }^{[20]}$.

\section{Statistical Analysis}

All statistical analyses were performed using Statistical Package for the Social Sciences (SPSS) version 16.0 for Windows (SPSS Inc., Chicago, IL, USA). Descriptive statistics were used to describe demographic characteristics. Spearman's rank correlation coefficients were calculated to determine the relationships between non parametric data. Differences between the clinical parameters by the radiographic grade were examined using analysis of variance. In all analyses, $P$ values $<0.05$ were considered statistically significant.

\section{Results}

One hundred and twenty-five patients with knee OA who visited the physical medicine and rehabilitation clinic, and were eligible for the current analysis were enrolled in this study. Their ages ranged between 32 and 87 (mean $56.71 \pm 10.05$ ) years.

On the radiographic assessment, 115 (46\%) knees were grade $2 \mathrm{~K}$-L scale, while 84 (33.6\%) knees were grade 3 showing that most of the patients fall in the range of mild to moderate for radiographic features of OA severity. The demographic details, clinical, and radiological characteristics of the patients are presented in Table 1. Table 2 shows the demographic data of the studied patients in different OA severity grades according to the $\mathrm{K}-\mathrm{L}$ grading scale. The detailed radiographic findings, including joint space narrowing grades, osteophyte sites and sizes in the 3 knee compartments, are shown in Table 3. Moderate narrowing of the medial TF joint was detected in $47.6 \%$ of patients. Medial and lateral TF joints were involved concurrently by osteophytes in $54.4 \%$ of patients. With regards to the PF joint, moderate narrowing was detected in $46.8 \%$ of cases with involvement of both the upper and lower margins with osteophytes in $52.4 \%$ of patients. Small sized osteophytes were reported in $42.8 \%$ and $48.8 \%$ of cases in the TF and PF joints

Table 1. Demographic features, clinical, and radiographic characteristics of the patients.

\begin{tabular}{|c|c|c|c|}
\hline \multicolumn{2}{|c|}{ Parameter } & Range & $($ mean $\pm S D)$ \\
\hline $\begin{array}{l}\text { Age(years) } \\
\text { BMI }\left(\mathrm{Kg} / \mathrm{m}^{2}\right) \\
\text { Disease duration(years) } \\
\text { WOMAC }\end{array}$ & $\begin{array}{c}\text { Pain } \\
\text { Stiffness Score } \\
\text { Physical Function } \\
\text { Total Score }\end{array}$ & $\begin{array}{c}32-87 \\
18.90-48.80 \\
1.0-20.0 \\
1.0-19.0 \\
0.00-8.0 \\
0.0-62.0 \\
3.0-96.0 \\
\end{array}$ & $\begin{array}{c}56.71 \pm 10.05 \\
31.16 \pm 5.69 \\
3.92 \pm 3.77 \\
10.81 \pm 2.27 \\
2.18 \pm 2.18 \\
23.28 \pm 13.49 \\
36.27 \pm 16.28\end{array}$ \\
\hline & & & $\mathrm{n}(\%)$ \\
\hline $\begin{array}{l}\text { BMI } \\
\text { Gender } \\
\text { K-L Scale }\end{array}$ & $\begin{array}{l}\text { Normal } \\
\text { Overweight } \\
\text { Obesity } \\
\text { Female } \\
\text { Male } \\
\text { Grade 0 } \\
\text { Grade1 } \\
\text { Grade2 } \\
\text { Grade3 } \\
\text { Grade } 4\end{array}$ & & $\begin{array}{c}18(14.40 \%) \\
32(25.60 \%) \\
75(60.00 \%) \\
114(91.20 \%) \\
11(8.80 \%) \\
9(3.60 \%) \\
12(4.80 \%) \\
115(46.0) \\
84(33.60 \%) \\
30(12.00 \%)\end{array}$ \\
\hline
\end{tabular}

SD: Standard Deviation; BMI: Body Mass Index; WOMAC: Western Ontario and McMaster Universities Osteoarthritis Index; K-L: Kellgren-Lawrence Scale. 
Relationship Between Clinical and Radiographic Findings in Osteoarthritis Knee: A Cross-Sectional Study

S.A. Mahran et al.

Table 2. Values of demographic variables and WOMAC scores between different radiographic grades.

\begin{tabular}{|l|c|c|c|c|c|c|c|c|c|}
\hline & \multicolumn{3}{|c|}{ K-L Grade 2 } & \multicolumn{3}{c|}{ K-L Grade 3 } & \multicolumn{3}{c|}{ K-L Grade 4 } \\
\hline & Mean & SD & Range & Mean & SD & Range & Mean & SD & Range \\
\hline Age & 54.09 & 9.75 & $32-75$ & 59.66 & 10.07 & $36-87$ & 60.41 & 10.64 & $45-80$ \\
\hline BMI & 31.13 & 5.32 & $18.9-44.4$ & 31.51 & 5.81 & $19.8-44.3$ & 30.54 & 6.99 & $19.6-48.8$ \\
\hline Pain Duration & 3.30 & 2.85 & $1-15$ & 4.34 & 4.30 & $1-20$ & 4.53 & 3.34 & $1-10$ \\
\hline WOMAC pain & 10.89 & 2.36 & $9-19$ & 10.85 & 2.42 & $9-19$ & 10.94 & 2.05 & $9-16$ \\
\hline WOMAC stiffness & 2.14 & 2.29 & $.0-8$ & 2.17 & 2.06 & $.0-7$ & 2.35 & 2.47 & $.0-8$ \\
\hline WOMAC function & 22.16 & 15.04 & $2-62$ & 24.10 & 12.23 & $.0-51$ & 24.82 & 12.25 & $8-49$ \\
\hline WOMAC total & 35.20 & 18.10 & $11-80$ & 37.12 & 15.00 & $10-27$ & 38.112 & 15.47 & $18-67$ \\
\hline
\end{tabular}

SD: Standard Deviation; BMI: Body Mass Index; WOMAC: Western Ontario and MCMaster Universities Osteoarthritis Index; K-L: Kellgren-Lawrence Scale.

Table 3. Detailed radiographic findings in the studied patients.

\begin{tabular}{|c|c|c|c|}
\hline \multicolumn{4}{|c|}{ Joint Space Narrowing n (\%) } \\
\hline & Medial TF Joint & Lateral TF Joint & PF Joint \\
\hline No Narrowing & $11(4.40 \%)$ & $117(46.80 \%)$ & $24(9.60 \%)$ \\
\hline Mild Narrowing & $42(16.80 \%)$ & $89(35.60 \%)$ & $69(27.60 \%)$ \\
\hline Moderate Narrowing & $119(47.60 \%)$ & $40(16.00 \%)$ & $93(37.20 \%)$ \\
\hline Sever Narrowing & $78(31.20 \%)$ & $4(1.60 \%)$ & $64(25.60 \%)$ \\
\hline \multicolumn{4}{|c|}{ 0steophyte Site n (\%) } \\
\hline \multicolumn{2}{|c|}{ TF Joint } & \multicolumn{2}{|l|}{ PF Joint } \\
\hline No Osteophytes & $44(17.60 \%)$ & No Osteophytes & $34(13.60 \%)$ \\
\hline Osteophytes at medial TF & $59(23.60 \%)$ & Osteophytes at upper border & $79(31.60 \%)$ \\
\hline 0steophytes at lateral TF & $11(4.40 \%)$ & Osteophytes at lower border & $6(2.40 \%)$ \\
\hline Osteophytes at both medial and lateral TF & $136(54.40 \%)$ & Osteophytes at both upper and lower borders & $131(52.40 \%)$ \\
\hline \multicolumn{4}{|c|}{ Osteophyte Size n (\%) } \\
\hline & TF Joint & \multicolumn{2}{|l|}{ PF Joint } \\
\hline No Osteophytes & $44(17.60 \%)$ & \multicolumn{2}{|l|}{$34(13.60 \%)$} \\
\hline Small 0steophytes & $107(42.80 \%)$ & \multicolumn{2}{|l|}{$122(48.80 \%)$} \\
\hline Medium Osteophytes & $70(28.00 \%)$ & \multicolumn{2}{|l|}{$67(26.80 \%)$} \\
\hline Large 0steophytes & $29(11.60 \%)$ & \multicolumn{2}{|l|}{$27(10.80 \%)$} \\
\hline
\end{tabular}

Table 4. Correlation between Kellgren-Lawrence radiographic scale and the detailed radiographic characteristics of the patients.

\begin{tabular}{|c|c|c|}
\hline \multirow[t]{2}{*}{ Detailed Radiographic Data $(\mathrm{N}=250)$} & \multicolumn{2}{|c|}{ KL Scale } \\
\hline & $\mathrm{R}$ & $p$ \\
\hline Narrowing at medial TFJ & .652 & 0.000 \\
\hline Narrowing at lateral TFJ & .375 & 0.000 \\
\hline Osteophyte size at TFJ & .627 & 0.000 \\
\hline Osteophyte site at TFJ & .345 & 0.000 \\
\hline Osteophyte size at PFJ & .364 & 0.000 \\
\hline Osteophyte site at PFJ & .292 & 0.000 \\
\hline Narrowing at PFJ & .453 & 0.000 \\
\hline
\end{tabular}

respectively. A highly significant positive correlation between the $\mathrm{K}-\mathrm{L}$ grading scale and each parameter of the detailed radiographic study was found; all with $p$ value of $<0.000$ (Table 4 ).

Table 5 demonstrates the significantly positive correlations found between the BMI and all WOMAC sub-scores, age of the patients and pain duration. Pain duration was also found to positively correlate with the physical function sub-score of WOMAC. None of the WOMAC sub-scores were found to be related with $\mathrm{K}-\mathrm{L}$ grading scale. On the other hand, all WOMAC sub-scores were found to have positive significant relation with each other $(p<0.01)$ as illustrated in Table 6. From all the detailed radiographic studies, only the osteophyte site at the PF joint is shown to 
Relationship Between Clinical and Radiographic Findings in Osteoarthritis Knee: A Cross-Sectional Study S.A. Mahran et al.

Table 5. Correlation between clinical parameters and functional disability score of the patients

\begin{tabular}{|l|l|c|c|c|c|c|}
\hline \multicolumn{1}{|c|}{ Clinical Parameter } & \multicolumn{1}{|c|}{ BMI(r) } & Pain Duration(r) & $\begin{array}{c}\text { WOMAC } \\
\text { Pain(r) }\end{array}$ & $\begin{array}{c}\text { WOMAC } \\
\text { Stiffness(r) }\end{array}$ & $\begin{array}{c}\text { WOMAC Function } \\
(\mathbf{r})\end{array}$ & W0MAC Total (r) \\
\hline Age & $-.259^{ \pm}$ & .096 & .042 & $-.013-$ & $-.021-$ & $-.013-$ \\
\hline BMl & 1.00 & $.205^{*}$ & $.199^{*}$ & $.373^{\ddagger}$ & $.199^{*}$ & $.242^{ \pm}$ \\
\hline Pain Duration & $.205^{*}$ & 1.00 & .126 & $-.040-$ & $.183^{*}$ & .164 \\
\hline
\end{tabular}

${ }^{*} P<0.05$ and ${ }^{ \pm} P<0.01$.

BMI: Body mass index, WOMAC: Western Ontario and McMaster Universities Osteoarthritis Index.

Table 6. Correlation between Kellgren-Lawrence radiographic scale and WOMAC scale, and correlations within the WOMAC scale.

\begin{tabular}{|l|c|c|c|c|}
\hline \multicolumn{1}{|c|}{ Parameter } & $\begin{array}{c}\text { WOMAC } \\
\text { Pain(r) }\end{array}$ & $\begin{array}{c}\text { WOMAC } \\
\text { Stiffness(r) }\end{array}$ & $\begin{array}{c}\text { WOMAC } \\
\text { Function }(r)\end{array}$ & $\begin{array}{c}\text { WOMAC Total } \\
(r)\end{array}$ \\
\hline Kellgren-Lawrence Scale & .049 & .024 & .082 & .073 \\
\hline WOMAC Pain & 1.00 & $.360^{*}$ & $.531^{*}$ & $.604^{*}$ \\
\hline WOMAC Stiffness & $.360^{*}$ & 1.00 & $.564^{*}$ & $.650^{*}$ \\
\hline WOMAC Function & $.531^{*}$ & $564^{*}$ & 1.00 & $.987^{*}$ \\
\hline
\end{tabular}

WOMAC: Western Ontario and McMaster Universities Osteoarthritis Index.

Table 7. Relationship between WOMAC scale and detailed radiographic findings (ANOVA)

\begin{tabular}{|l|c|c|c|c|}
\hline & $\begin{array}{c}\text { WOMAC } \\
\text { Pain (F) }\end{array}$ & $\begin{array}{c}\text { WOMAC } \\
\text { Stiffness (F) }\end{array}$ & WOMAC Function(F) & $\begin{array}{c}\text { WOMAC } \\
\text { Total(F) }\end{array}$ \\
\hline K-L scale & .580 & .035 & .805 & .663 \\
\hline Narrowing Medial TFJ & .277 & .028 & 1.160 & .791 \\
\hline Narrowing Lateral TFJ & .316 & 1.816 & .194 & .248 \\
\hline Narrowing PFJ & .360 & .901 & 1.025 & 1.046 \\
\hline Osteophytes Size TFJ & .339 & .076 & .235 & .131 \\
\hline Osteophytes Site TFJ & .285 & .077 & .638 & .520 \\
\hline Osteophytes Size PFJ & .253 & 2.232 & .479 & .613 \\
\hline Osteophytes Site PFJ & .542 & $3.459^{*}$ & .409 & .676 \\
\hline
\end{tabular}

${ }^{*} P<0.05$

ANOVA: Analysis of Variance; WOMAC: Western Ontario and McMaster Universities Osteoarthritis Index.; K-L = Kellgren Lawrence radiographic scale; TFJ= Tibiofemoral joint; $P F J=$ Patellofemoral joint.

have a significant positive correlation with the WOMAC stiffness sub-score $(P<0.05)$ as shown in Table 7.

\section{Discussion}

This cross-sectional study investigated the relationship between the radiographic status of patients with knee $\mathrm{OA}$, and their clinical manifestations and functional capabilities. This study also investigated whether the use of detailed analysis of individual radiographic features was superior to the general K-L scale in establishing such a relation. To the authors' current knowledge, no previous inquiry into the relationship between the detailed radiographic changes - in the form of degree of joint space narrowing and osteophytes' site and size - and the WOMAC severity index in patients with knee OA has been published.

Obesity is a well-documented and important risk factor for the development of knee $\mathrm{OA}^{[22-24]}$.
These results demonstrate that BMI was significantly correlated with all WOMAC sub-scores. In a recent study, Weiss found that when taking into account OA severity, individuals with a higher BMI experience greater pain than individuals with a lower BMI, and that weight loss may reduce knee OA pain even if the osteological symptoms remain untreated ${ }^{[25]}$.

In this study, WOMAC sub-scores were found to correlate with the age of the patients and pain duration. McAlindon et al. ${ }^{[14,26]}$ demonstrated that knee pain and age are more important determinants of functional impairments in elderly subjects than the severity of knee $\mathrm{OA}$ as assessed by radiographic features.

Due to the fact that pain is the main complaint and the primary cause of physical disability among patients with knee $O A^{[27]}$, and as the risk of disability increases with the presence of knee pain in the community ${ }^{[7,28,29]}$, knee pain was chosen as the clinical parameter of knee 
OA in the studies that investigate the relation between the clinical and radiological severity of knee OA. In the current study, an association between $\mathrm{K}-\mathrm{L}$ grading scale and WOMAC subsccore (pain, stiffness and physical function) could not be established. However, when detailed radiographic analysis was used, the osteophyte site at the PF joint was found to correlate with the WOMAC stiffness sub-score.

There is a widespread belief that a high discrepancy exists between clinical and radiographic knee $\mathrm{OA}^{[30-32]}$. A number of authors report that they have failed to find a strong association between pain scores and radiographic changes s,33-37] $^{\text {. The postulated }}$ reason behind such discordance is the variability in radiographic definition of $\mathrm{OA}$, which affects the number of cases diagnosed to have the disease and therefore the prevalence of radiographic OA disease. For example, in the knee the joint contains three compartments and if the only X-rays considered are the PA view, then only osteoarthritis in the medial and lateral compartments would be identified, and up to $24 \%$ of patients with radiographic knee $O A$ would be undiagnosed due to failure to visualize the PF joint ${ }^{[38]}$. This study aimed to avoid this pitfall by having the 3 compartments of the knee - including the PF compartment - examined by radiograph. On the other hand, some studies ${ }^{[26,35,39,40]}$ have found that radiographic features of osteoarthritis were significantly associated with knee pain. Results from an observational study have demonstrated that there was a strong dose-response relation of the severity of radiographic knee OA to the prevalence of frequent knee pain, consistent frequent knee pain and pain severity ${ }^{[41]}$.

Fewer studies attempt to link radiographic changes with function. This study was unable to establish an association between the grades of radiographic changes, and the functional disabilities of the patients in the form of physical function sub-score of WOMAC index. This is consistent with Larsson et al. ${ }^{[42,43]}$ who reported that radiographic diagnosis of osteoarthritis was not related to functional capacity. Creamer et al. ${ }^{[44]}$ found that function was determined by pain and obesity rather than by structural changes as seen on X-ray.

Potential limitations of this study are its crosssectional design rather than longitudinal follow up. Moreover only the WOMAC scale was used, which reflects subjective data rather than the actual functional level of patients.
The authors conclude that the relationship between the radiographic and the clinical features of knee $O A$ is not well established and that the radiographic assessment alone is of limited benefit in predicting the functional level of the patient. It is suggested that to choose among the available management plans for knee OA, either rehabilitation or surgery, both the clinical and radiographic evaluation are to be considered. Additional longitudinal studies using objective clinical measures of knee OA, such as the quadriceps muscle strength or range of motion, are recommended for more accurate identification of the rate of radiological changes and its relationship with the functional level of the patients.

\section{Conflict of Interest}

The authors have no conflict of interest.

\section{Disclosure}

None of the authors received any type of commercial support either in forms of compensation or financial for this study. They have no financial interest in any of the products or devices, or drugs mentioned in this article.

\section{Ethical Approval}

Obtained.

\section{References}

[1] Felson DT, Naimark A, Anderson J, Kazis L, Castelli W, Meenan RF. The prevalence of knee osteoarthritis in the elderly. The Framingham Osteoarthritis Study. Arthritis Rheum 1987; 30(8): 914-918.

[2] Puett DW, Griffin MR. Published trials of nonmedicinal and noninvasive therapies for hip and knee osteoarthritis. Ann Intern Med 1994; 121(2): 133-140.

[3] Davis MA. Epidemiology of osteoarthritis. Clin Geriatr Med 1988; 4(2): 241-255.

[4] Hunter DJ, Felson DT. Osteoarthritis. BMJ 2006; 332(7542): 639-642.

[5] Hopman-Rock M, Odding E, Hofman A, Kraaimaat FW, Bijlsma JW. Physical and psychosocial disability in elderly subjects in relation to pain in the hip and/or knee. J Rheumatol 1996; 23(6): 1037-1044.

[6] Jordan J, Luta G, Renner J, Dragomir A, Hochberg M, Fryer J. Knee pain and knee osteoarthritis severity in self-reported task specific disability: the Johnston County Osteoarthritis Project. J Rheumatol 1997; 24(7): 1344-1349.

[7] Davis MA, Ettinger WH, Neuhaus JM, Mallon KP. Knee osteoarthritis and physical functioning: evidence from the 
Relationship Between Clinical and Radiographic Findings in Osteoarthritis Knee: A Cross-Sectional Study S.A. Mahran et al.

NHANES I epidemiological follow up study. J Rheumatol 1991; 18(4): 591-598.

[8] Bellamy N, Buchanan WW, Goldsmith CH, Campbell J, Stitt LW. Validation study of WOMAC: a health status instrument for measuring clinically important patient relevant outcomes to antirheumatic drug therapy in patients with osteoarthritis of the hip or knee. J Rheumatol 1988; 15(12): 1833-1840.

[9] Salaffi F, Carotti M, Grassi W. Health-related quality of life in patients with hip or knee osteoarthritis: comparison of generic and disease-specific instruments. Clin Rheumatol 2005; 24(1): 29-37.

[10] KELLGREN JH, LAWRENCE JS. Radiological assessment of osteoarthrosis. Ann Rheum Dis 1957; 16(4): 494-502.

[11] Buckland-Wright JC, Ward RJ, Peterfy C, Mojcik CF, Leff RL. Reproducibility of the semiflexed (metatarsophalangeal) radiographic knee position and automated measurements of medial tibiofemoral joint space width in a multicenter clinical trial of knee osteoarthritis. J Rheumatol 2004; 31 (8): 1588-1597.

[12] Conrozier $T$, Lequesne $M$, Favret $H$, Taccoen $A$, Mazières $B$, Dougados M, Vignon M, Vignon E. Measurement of the radiological hip joint space width: An evaluation of various methods of measurement. Osteoarthr Cartil 2001; 9(3): 281-286.

[13] Lanyon P, O'Reilly S, Jones A, Doherty M. Radiographic assessment of symptomatic knee osteoarthritis in the community: definitions and normal joint space. Ann Rheum Dis 1998; 57(10): 595-601.

[14] McAlindon TE, Snow S, Cooper C, Dieppe PA. Radiographic patterns of osteoarthritis of the knee joint in the community: the importance of the patellofemoral joint. Ann Rheum Dis 1992; 51(7): 844-849.

[15] Peat G, Thomas E, Duncan R, Wood L, Wilkie R, Hill J, Hay EM, Croft P. Estimating the probability of radiographic osteoarthritis in the older patient with knee pain. Arthritis Care Res 2007; 57(5): 794-802.

[16] Bedson J, Croft PR. The discordance between clinical and radiographic knee osteoarthritis: A systematic search and summary of the literature. BMC Musculoskelet Disord 2008; 9: 116.

[17] Altman RD. Criteria for classification of clinical osteoarthritis. J Rheumatol Suppl 1991; 27: 10-12.

[18] [No authors listed]. Physical status: the use and interpretation of anthropometry. Report of a WHO Expert Committee. World Health Organ Tech Rep Ser 1995; 854: $1-452$.

[19] [No authors listed]. "Western Ontario and McMaster Universities Osteoarthritis Index (WOMAC)--General Description". ACR Accessed 18 May 2015.

[20] Nagaosa Y, Mateus M, Hassan B, Lanyon P, Doherty M. Development of a logically devised line drawing atlas of grading of knee osteoarthritis. Ann Rheum Dis 2000; 59(8): 587-595.
[21] Chaisson C E, Gale D R, Kazis L Kazis L, Skinner K, Felson DT. Detecting radiographic knee osteoarthritis: what combination of views is better? Rheumatology 2000; 39: 1218-1221.

[22] Grotle M, Hagen K, Natvig B. Obesity and osteoarthritis in knee, hip and/or hand: an epidemiological study in the general population with 10 years follow-up. BMC Musculoskelet Disord 2008; 9: 132-136.

[23] Felson DT, Lawrence RC, Dieppe PA, Hirsch R, Helmick CG, Jordan JM, Kington RS, Lane NE, Nevitt MC, Zhang Y, Sowers M, McAlindon T, Spector TD, Poole AR, Yanovski SZ, Ateshian G, Sharma L,Buckwalter JA, Brandt KD, Fries JF. Osteoarthritis: new insights. Part 1: the disease and its risk factors. Ann Intern Med 2000; 133(8): 635-646.

[24] Lawrence RC, Felson DT, Helmick CG, Arnold LM, Choi H, Deyo RA, Gabriel S, Hirsch R, Hochberg MC,Hunder GG, Jordan JM, Katz JN, Kremers HM, Wolfe F; National Arthritis Data Workgroup. Estimates of the prevalence of arthritis and other rheumatic conditions in the United States. Part II. Arthritis Rheum 2008; 58(1): 26-35.

[25] Weiss E. Knee osteoarthritis, body mass index and pain: data from the Osteoarthritis Initiative. Rheumatology (Oxford) 2014; 53(11): 2095-2099.

[26] McAlindon TE, Cooper C, Kirwan JR, and Dieppe PA. Determinants of disability in osteoarthritis of the knee. Ann Rheum Dis 1993; 52(4): 258-262.

[27] Torres L, Dunlop DD, Peterfy C, Guermazi A, Prasad P, Hayes KW, Song J, Cahue S, Chang A, Marshall M, Sharma $\mathrm{L}$. The relationship between specific tissue lesions and pain severity in persons with knee osteoarthritis. Osteoarthritis Cartilage 2006; 14(10): 1033-1040.

[28] Guccione AA, FelsonDT, Anderson JJ. Defining arthritis and measuring functional status in elders: methodological issues in the study of disease and physical disability. Am J Public Health 1990; 80(8): 945-949.

[29] Davis MA, Ettinger WH, Neuhaus JM, Barclay JD, Segal MR. Correlates of knee pain among US adults with and without radiographic knee osteoarthritis. J Rheumatol 1992; 19(12): 1943-1949.

[30] Hart DJ, Spector TD, Brown P, Wilson P, Doyle DV, Silman AJ. Clinical signs of early osteoarthritis: Reproducibility and relation to $x$ ray changes in 541 women in the general population. Ann Rheum Dis 1991; 50(7): 467-470.

[31] Felson DT. The epidemiology of knee osteoarthritis: results from the Framingham Osteoarthritis Study. Semin Arthritis Rheum 1990; 20(3 Suppl 1): 42-50.

[32] Claessens AA, Schouten JS, van den Ouweland FA, Valkenburg HA. Do clinical findings associate with radiographic osteoarthritis of the knee? Ann Rheum Dis 1990; 49(10): 771-774.

[33] Salaffi F, Cavalieri F, Nolli M, Ferraccioli G .Analysis of disability in knee osteoarthritis. Relationship with age and 
Relationship Between Clinical and Radiographic Findings in Osteoarthritis Knee: A Cross-Sectional Study S.A. Mahran et al.

psychological variables but not with radiographic score. J Rheumatol 1991; 18(10): 1581-1586.

[34] Madsen OR, Bliddal H, Egsmose C, Sylvest J. Isometric and isokinetic quadriceps strength in gonarthrosis; interrelations between quadriceps strength, walking ability, radiology, subchondral bone density and pain. Clin Rheumatol 1995; 14(3): 308-314.

[35] Cicuttini FM, Baker J, Hart DJ, Spector TD. Association of pain with radiological changes in different compartments and views of the knee joint. Osteoarthritis Cartilage 1996; 4(2): 143-147.

[36] Szebenyi B, Hollander AP, Dieppe P, Quilty B, Duddy J, Clarke $S$, Kirwan JR. Associations between pain, function, and radiographic features in osteoarthritis of the knee. Arthritis Rheum 2006; 54(1): 230-235.

[37] Hannan MT, Felson DT, Pincus T. Analysis of the discordance between radiographic changes and knee pain in osteoarthritis of the knee. J Rheumatol 2000; 27(6): 15131517.

[38] Lanyon P, O'Reilly S, Jones A, Doherty M. Radiographic assessment of symptomatic knee osteoarthritis in the community: definitions and normal joint space. Ann Rheum Dis 1998; 57(10): 595-601.

[39] Lethbridge-Cejku M, Scott WW Jr, Reichle R, Ettinger WH, Zonderman A, Costa P, Plato CC, Tobin JD, Hochberg MC Association of radiographic features of osteoarthritis of the knee with knee pain: data from the Baltimore Longitudinal Study of Ageing. Arthritis Care Res 1995; 8(3): 182-188.

[40] Duncan R, Peat G, Thomas E, Hay EM, McCall I, Croft P. Symptoms and radiographic osteoarthritis: not as discordant as they are made out to be? Ann Rheum Dis 2007; 66(1): 86-91.

[41] Neogi T, Felson D, Niu J, Nevitt M, Lewis CE, Aliabadi P, Sack B, Torner J, Bradley L, Zhang Y. Association between radiographic features of knee osteoarthritis and pain: results from two cohort studies. BMJ 2009; 339: b2844.

[42] Larsson AC, Petersson I, Ekdahl C. Functional capacity and early radiographic osteoarthritis in middle-aged people with chronic knee pain. Physiother Res Int 1998; 3(3): $153-$ 163.

[43] Bruyere O, Honore A, Rovati LC, Giacovelli G, Henrotin YE, Seidel L, Reginster YV. Radiologic features poorly predict clinical outcomes in knee osteoarthritis. Scand J Rheumatol 2002; 31(1): 13-16.

[44] Creamer P, Lethbridge-Cejku M, Hochberg MC. Factors associated with functional impairment in symptomatic knee osteoarthritis. Rheumatology 2000; 39(5): 490-496. 
العلاقة بين التتائج السريرية والإشعاعية في مرض التهاب الركبة: دراسة مستعرضة

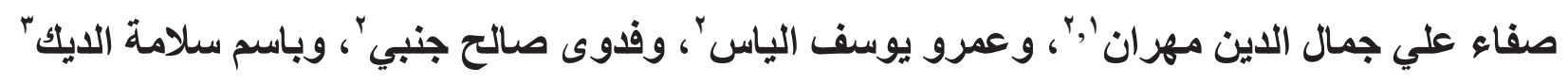

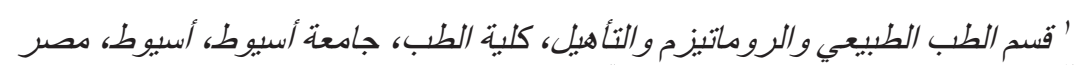

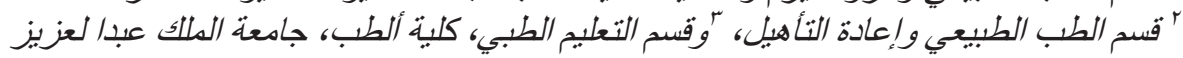
جدة ـ المملكة العربية السعودية العادة التية

العستخلص. أثنارت العديد من الدراسات أن وجود تباين كبير بين التقييم السريري والتقييم الإشعاعي لالتهاب مفاصل

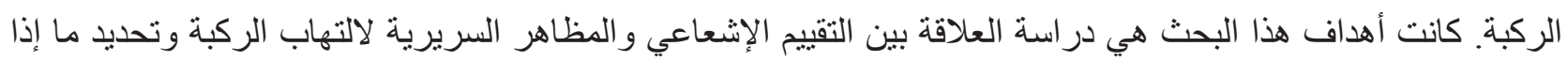
كان الدراسة التفصيلية للتصوير الإشعاعي تتفوق على الدراسة العامة للتصوير الإشعاعي في ايجاد مثل هذه العلاقة. وقد

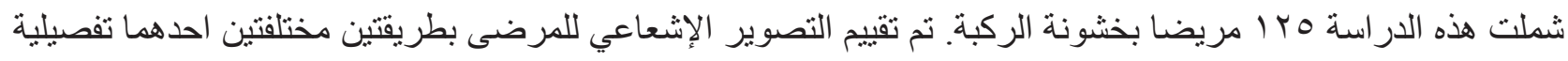
باستخدام اطلس مرسوم والأخرى عامه باستخدام مقياس (كالجرن لورانس) كما نم استخدام مؤشر الجامعات أونتاريو وماكماستر الغربيتين (WOMAC) لالتهاب المفاصل و التي تشمل قياس شدة آلام ألركبة والتصلب، و العجز. كانت النتائج

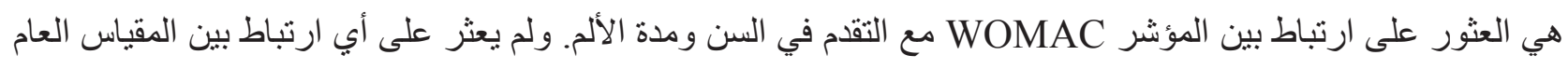

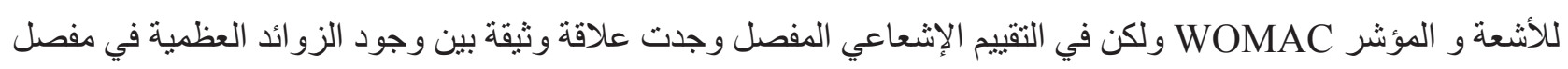
رضفة الفخذ مع تصلب المفصل المصاب. وفي الختام، لم ينم العثور على ارتباط وثيق بين نتيجة التصوير الإشعاعي

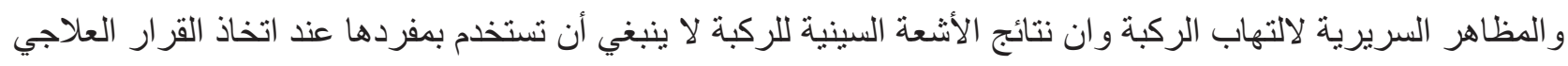
لمرضى التهاب الركبة. 